\title{
PENGENALAN IRIS MATA MENGGUNAKAN METODE TEMPLATE MATCHING CORRELATION
}

\author{
Sayuti Rahman ${ }^{1}$, Ulfa Sahira ${ }^{2}$, Nenna Irsa Syahputri ${ }^{3}$ \\ Program Studi Teknik Informatika Universitas Harapan Medan \\ J1. Hm Jhoni No. 70 Medan, Indonesia \\ 'masay.ramegmail.com, ${ }^{2}$ ulfasahiral8egmail.com
}

\begin{abstract}
ABSTRAK - Biometrik merupakan studi tentang metode otomatis untuk mengenali manusia berdasarkan satu atau lebih bagian tubuh manusia yang memiliki keunikan. Salah satu karakteristik manusia yang dapat digunakan yaitu iris mata, fitur-fitur iris mata dapat dijadikan karakteristik pembeda dengan individu lain. Tahap yang penulis lakukan untuk dapat mengenali pola iris mata seseorang dalam sebuah citra digital adalah tahap pre-processing, tahap simpan template dan tahap pencocokan. Pada penelitian ini penulis menerapkan metode template matching untuk menyimpan citra agar menjadi citra template yang disimpan dalam database dan algoritma correlation coefficient untuk algoritma pencocokan ciri antara data template dan data uji. Aplikasi dirancang menggunakan bahasa pemrograman Matlab R2010a. Hasil pengujian 22 citra didapatkan persentasi keberhasilan sistem adalah $86,36 \%$.

Kata Kunci - Iris, Template Matching, Correlation Coefficient
\end{abstract}

ABSTACT - Biometrics is the study of automated methods for recognizing human beings based on one or more parts of the human body that have uniqueness. One of the human characteristics that can be used is the iris, iris features can be used as distinguishing characteristics with other individuals. The stage that writers do to be able to recognize the slice pattern of a person's eyes in a digital image is the pre-processing stage, the template save stage and the matching stage. In this study the authors apply the template matching method to store the image to be a template image stored in the database and the correlation coefficient algorithm for the feature matching algorithm between template data and test data. The application is designed using Matlab R2010a programming language. The result of testing 22 images obtained percentage of system success is $86,36 \%$.

Keywords - Iris, Template Matching, Correlation Coefficient

\section{PENDAHULUAN}

Tidak dapat dipungkiri bahwa perkembangan teknologi informasi saat ini telah membawa dampak bagi kehidupan manusia. Salah satu teknologi yang sangat berpengaruh yaitu komputer. Komputer adalah suatu alat teknologi yang dapat digunakan untuk membuat atau merancang suatu sistem. Kebutuhan sistem semakin meningkat seperti sistem pengenalan diri untuk sistem keamanan. Sistem pengenalan bertujuan untuk memecahkan suatu identitas seseorang. Sistem pengenalan memiliki dua tipe yaitu sistem verifikasi dan identifikasi[1]. Sistem pengenalan yang dirancang pada penelitian ini menggunakan sistem identifikasi. Salah satu teknik identifikasi yang mampu mengenali karakter biologis individu dikenal dengan nama biometrik. Biometrik adalah suatu teknik untuk mengenali manusia berdasarkan satu atau lebih bagian tubuh manusia yang memiliki keunikan seperti iris mata, retina mata, wajah, sidik jari, telapak tangan dan suara.

Iris mata merupakan salah satu organ tubuh manusia yang memiliki keunikan. Iris adalah bagian mata yang memiliki berbagai pigmen, tekstur dan pola yang berbeda, bahkan tekstur iris setiap orang antara mata kanan dan kiri pun tidak sama.

Pengenalan iris mata ini menggunakan metode Template Matching Correlation. Template matching merupakan untuk mengukur kesamaan dari citra dengan citra template, dengan pencarian fitur tertentu dari keduanya. Kesamaan dari dua buah citra dapat dihitung nilainya dengan cara menghitung nilai korelasi (correlation).
Dalam penelitian ini penulis merancang aplikasi pengenalan iris mata menggunakan metode Template matching correlation. Penelitian sebelumnya yang berhubungan dengan topik pengenalan iris mata ini sudah pernah diteliti oleh Eky Yuliansyah, dkk, 2017 dengan menggunakan metode Independent Component Analysis dan K-Nearest Neighbor [3]. Lukman Hakim, dkk, 2017 dengan menggunakan Threshold Linear dan Garis Horizontal Imajiner[12]. Andriana dan Zulkarnain, 2014 dengan menggunakan GLCM (Gray Level Co Matrix) dan Hough Transform[13].

\section{A. Biometrik}

\section{LANDASAN TEORI}

Biometrik adalah suatu teknik untuk mengenali manusia melalui karakteristik biologi dari satu atau lebih bagian tubuh manusia yang memiliki keunikan. Biometrik termasuk memiliki dua karakter yaitu karakteristik alami manusia, yaitu karakteristik Physiological (fisiologi) adalah karakteristik yang dihubungkan dengan bentuk tubuh contohnya sidik jari, wajah, telapak tangan, iris dan retina mata. Dan karakteristik Behavioral adalah karakteristik yang dihubungkan dengan tingkah laku contohnya cara mengetik, tanda tangan dan suara.

\section{B. Citra}

Citra adalah kumpulan dari titik, garis, bidang dan warna untuk menciptakan suatu objek yang dapat juga menjelaskan suatu informasi atau keterangan. Citra diartikan sebagai fungsi dari dua variabel misalnya $a(x, y)$ dimana $a$ sendiri amplitude citra pada koordinat $(x, y)[6]$. Citra terbagi dua yaitu citra analog dan citra digital. Citra analog adalah citra yang bersifat kontinu 
seperti lukisan, foto yang dapat terlihat oleh kasat mata. Sedangkan citra digital adalah citra yang bernilai diskrit (pixel) sehingga dapat diolah oleh komputer.

\begin{tabular}{|c|cccc|}
\hline \multicolumn{1}{c|}{ Koordinat asal } \\
\end{tabular}

Gambar 1. Koordinat Citra Digital

Definisi citra secara matematis terlihat seperti dibawah ini :

$$
f(x, y)=\left[\begin{array}{cccc}
f(0,0) & f(0,1) & \ldots & f(0, N-1) \\
f(1,0) & f(1,1) & \ldots & f(1, N-1) \\
\vdots & \vdots & : & : \\
f(M-1,0) & f(M-1,1) & \ldots & f(M-1, N-1)
\end{array}\right]
$$

Gambar 2. Nilai Matrik Pada Citra Digital

Dimana $\mathrm{f}(\mathrm{x}, \mathrm{y})$ merupakan fungsi intensitas, $x$ menunjukkan baris dan $y$ menunjukkan kolom.

\section{Pengolahan Citra Digital}

Pengolahan citra digital adalah ilmu yang mengolah sinyal yang berupa gambar. Mempelajari hal yang berkaitan dengan perbaikan kualitas citra, melakukan penarikan informasi yang terkandung dalam citra dan melakukan kompresi data untuk tujuan penyimpanan data, transmisi data, waktu proses data. Pengolahan citra digital memiliki hubungan yang erat dengan disiplin ilmu lain. Jika sebuah disiplin ilmu dinyatakan dalam bentuk proses suatu input menjadi output, ada beberapa ilmu yang berkaitan yaitu Grafika komputer (computer graphics) cabang ilmu informatika yang memproses/mengolah data input berupa deskripsi menjadi output berupa citra. Pengolahan citra (image processing) memiliki input berupa citra serta output juga berupa citra. Pengenalan pola (pattern recognition) menerjemahkan citra menjadi deskripsi.

\section{Pengenalan Pola}

Pengenalan pola merupakan untuk menentukan kelompok atau kategori pola berdasarkan ciri-ciri yang dimiliki oleh pola tersebut. Apabila ciri yang memiliki daya pembeda yang tinggi, maka pengelompokan pola berdasarkan ciri yang dimiliki dapat dilakukan dengan nilai keakuratan yang tinggi. Pengenalan pola memiliki dua pendekatan yaitu pengenalan pola secara statistik dan pengenalan pola sintatik.

\section{E. Visi komputer}

Visi komputer (computer vision) adalah bidang yang mencakup metode untuk memperoleh mengolah menganalisis dan memahami data visual seperti gambar dan video. Visi komputer bertujuan agar komputer atau mesin dapat meniru kemampuan perseptual mata dan otak manusia.

\section{F. Template Matching}

Template matching merupakan untuk mengukur kesamaan dari citra dengan citra template, dengan pencarian fitur tertentu dari keduanya. Template matching memiliki kelebihan dan kekurangan. Kelebihannya adalah metode ini mudah untuk dituliskan ke dalam bahasa program dan mudah untuk mempersiapkan data referensinya. Kekurangannya adalah membutuhkan data referensi atau basis data yang banyak untuk mendapatkan hasil yang optimal.

\section{G. Correlation}

Correlatian (korelasi) adalah lebih mencari kesamaan dibanding ketidaksamaan. Correlation yaitu pengurangan nilai koordinat dengan nilai mean, yang memiliki nilai diantara -1 dan 1 . Jadi semakin tinggi nilainya menunjukkan 2 vektor semakin mirip[10]. Correlation coefficient disebut juga Pearsons correlation atau standardized covariance. Berikut ini persamaannya :

Korelasi $=r_{x y}=\frac{S_{x y}}{S_{x} \cdot S_{y}}$

atau

Korelasi $=r_{x y}=\frac{\sum\left(x_{i}-\bar{x}\right)\left(y_{i}-\bar{y}\right)}{\sqrt{\sum\left(x_{i}-\bar{x}\right)^{2}} \cdot \sqrt{\sum\left(y_{i}-\bar{y}\right)^{2}}}$

atau

Korelasi $=r_{x y}=\frac{\sum x_{i} y_{i}-\frac{\sum x_{i} \sum y_{i}}{n}}{\sqrt{\sum x_{i}^{2}-\frac{\left(\sum x_{i}\right)^{2}}{n}} \cdot \sqrt{\sum y_{i}^{2}-\frac{\left(\sum y_{i}\right)^{2}}{n}}}$

atau

Korelasi $=r_{x y}=\frac{n \sum x_{i} y_{i}-\sum x_{i} \sum y_{i}}{\sqrt{n \sum x_{i}^{2}-\left(\sum x_{i}\right)^{2}} \cdot \sqrt{n \sum y_{i}^{2}-\left(\sum y_{i}\right)^{2}}}$

Dimana cov atau $S_{X Y}$ dirumuskan dengan persamaan :

Covarian $=S_{x y}=\frac{\sum\left(x_{i}-\bar{x}\right)\left(y_{i}-\bar{y}\right)}{n-1}$

Dimana $S x$ dan $S y$ dirumuskan dengan persamaan:

$S_{x}=\sqrt{\frac{\sum\left(x_{i}-\bar{x}\right)^{2}}{n-1}}$ dan $S_{y}=\sqrt{\frac{\sum\left(y_{i}-\bar{y}\right)^{2}}{n-1}}$

Keterangan :

$r_{x y}=$ nilai dari korelasi dua buah matriks (misalnya antara -1 sampai 1)

$x i \quad=$ nilai piksel dalam matriks $\mathrm{x}$

$y i \quad=$ nilai piksel dalam matriks $\mathrm{y}$

$\bar{x} \quad=$ nilai rata-rata matriks $\mathrm{x}$

$\bar{y} \quad=$ nilai rata-rata matriks $\mathrm{y}$

Cov = hubungan antara dua variabel yang dinilai dari cross-product deviation

Sx = standart deviation variabel $\mathrm{x}$

Sy = standart deviation variabel $\mathrm{y}$ 
$\mathrm{n} \quad=$ menyatakan jumlah piksel dalam suatu matriks

\section{METODOLOGI PENELITIAN}

Metodologi penelitian yang dilakukan pada penelitian ini meliputi :

1. Studi Literatur

Tahap ini dilakukan dengan cara mencari dan menggali informasi yang berhubungan dengan penelitian ini, baik dari buku, jurnal, internet dan sumber lainnya yang mendukung penelitian ini.

2. Pengumpulan Data

Tahap ini dilakukan dengan cara memfoto iris mata dari beberapa relasi menggunakan kamera handphone.

3. Desain atau Pemodelan Sistem

Tahap ini dilakukan dengan cara membuat rancangan sistem pengenalan iris mata yang terdapat dua tahap yaitu tahap pelatihan dan tahap pengujian.

4. Simulasi

Tahap simulasi ini dilakukan dengan cara menggunakan Matlab R2010a.

5. Pengujian

Tahap ini dilakukan pengujian terhadap sistem yang telah dibangun untuk melihat keluaran dari setiap tahapan.

\section{HASIL DAN PEMBAHASAN}

\section{A. Flowchart}

Flowchart adalah bagan dengan simbol-simbol tertentu yang memiliki fungsi masing-masing. flowchart yaitu menggambarkan urutan atau langkahlangkah proses secara mendetail dan hubungan antara suatu proses/instruksi dengan proses lainnya dalam suatu program.

\section{1) Flowchart Pre-processing}

Flowchart pre-processing yang telah dirancang dapat dilihat pada gambar berikut :

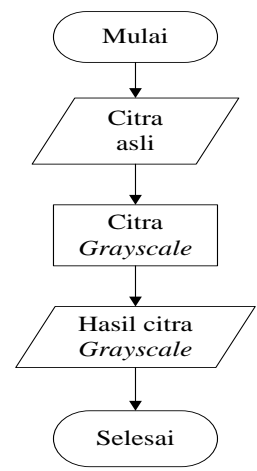

Gambar 3. Flowchart Pre-processing

\section{2) Flowchart Proses Pelatihan}

Flowchart proses pelatihan yang telah dirancang dapat dilihat pada gambar berikut :

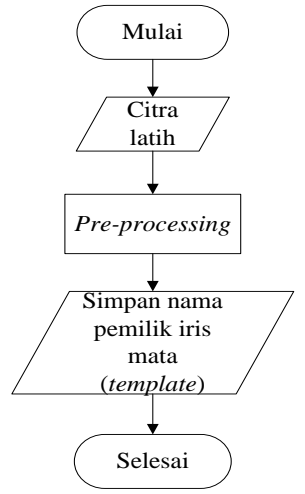

Gambar 4. Flowchart Proses Pelatihan

3) Flowchart Proses Pengujian

Flowchart proses pengujian yang telah dirancang dapat dilihat pada gambar berikut :

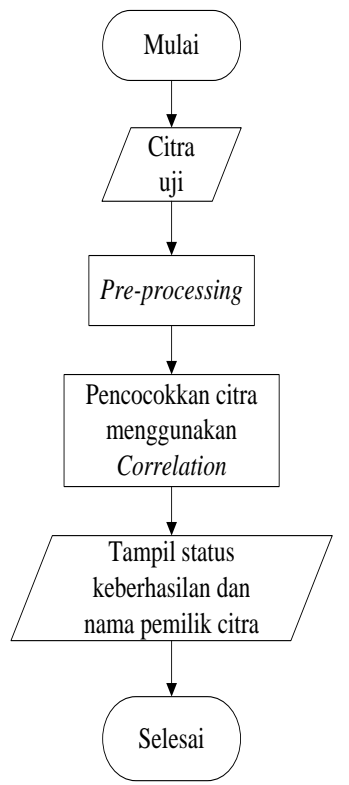

Gambar 5. Flowchart Proses Pengujian

B. $D F D$

DFD adalah diagram yang menjelaskan alur data, "dari mana dan ke mana sebuah data akan mengalir". DFD merupakan perangkat-perangkat analisis dan perancangan yang terstruktur sehingga penganalisis memahami sistem dan subsistem secara visual sebagai suatu rangkaian aliran data yang saling berkaitan.

\section{1) Diagram Konteks atau DFD level 0}

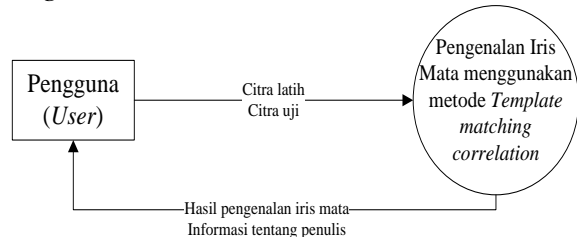

Gambar 6. Diagram Konteks 
2) DFD Level 1

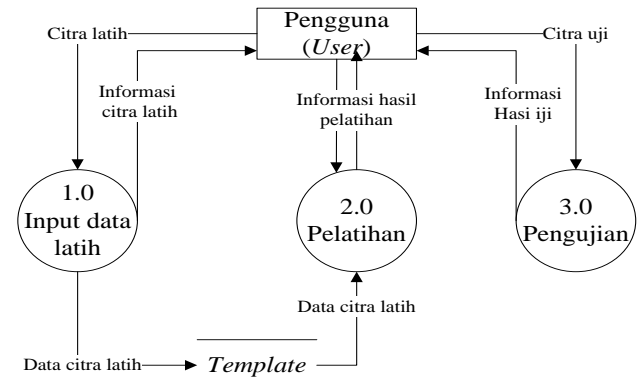

Gambar 7. DFD Level 1

3) DFD Level 2

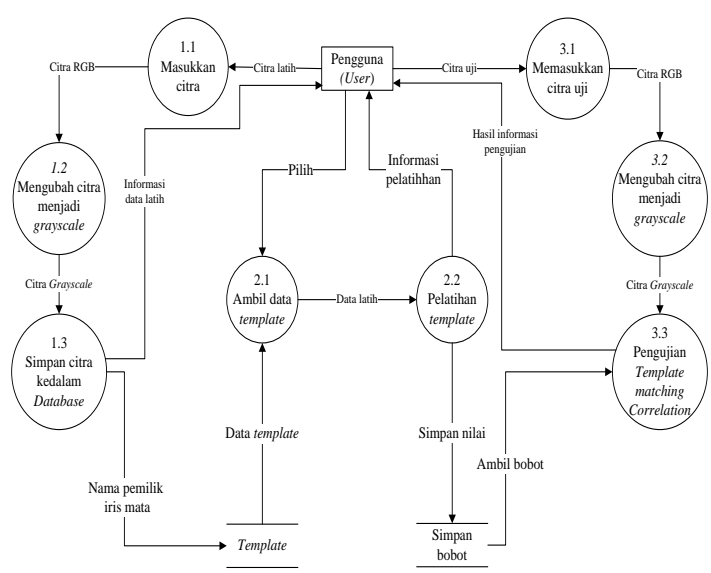

Gambar 8. DFD Level 2

\section{Matlab R2010a}

MATLAB singkatan dari MATrix LABoratory, merupakan bahasa pemrograman yang dikembangkan oleh The Mathwork Inc. MATLAB adalah bahasa tingkat tinggi banyak digunakan untuk perhitungan numerik, komputasi, simbolik, visualisasi, grafis, analisis data matematis, statiska, pemodelan, dan desain GUI (grafhical user interface). Bahasa pemrogramannya didasarkan pada matriks (baris dan kolom). MATLAB berisi toolbox yang mencakup fungsi-fungsi tambahan untuk aplikasi khusus. Window ini muncul pertama kali saat menjalankan program MATLAB.

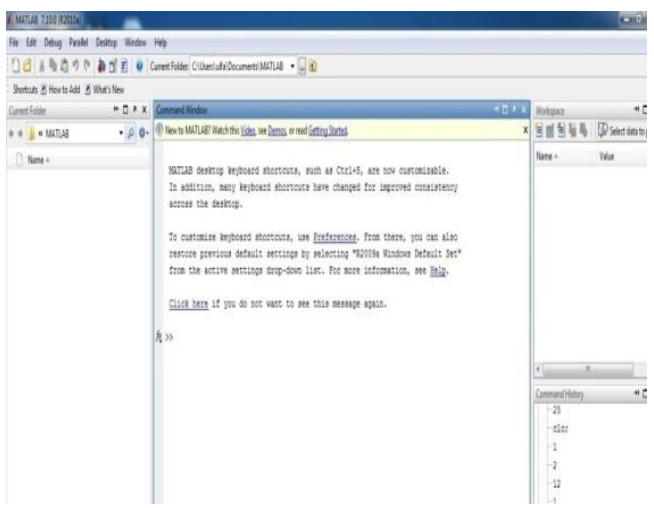

Gambar.9 Tampilan Awal MATLAB
D. Hasil

Hasil yang didapatkan dari perancangan sistem pengenalan iris mata menggunakan metode template matching correlation adalah sebagai berikut :

1) Tampilan Awal Aplikasi

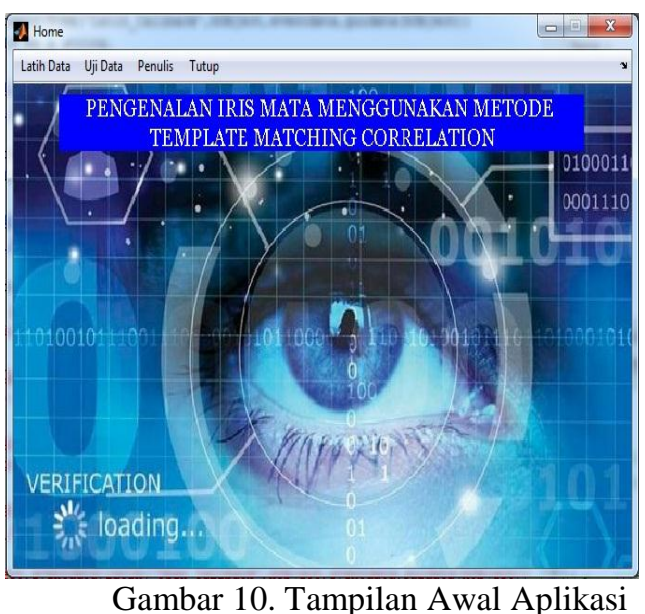

Pada gambar 10 terdapat judul tugas akhir dan empat menu utama yaitu latih data, uji data, penulis dan tutup. Menu latih data digunakan untuk menambahkan data latih. Menu uji data digunakan untuk menguji data uji dengan data latih apakah memiliki kecocokan satu sama lain. Menu penulis berisi tentang identitas penulis. Menu tutup untuk menutup aplikasi tersebut.

\section{2) Tampilan Menu Latih Data}

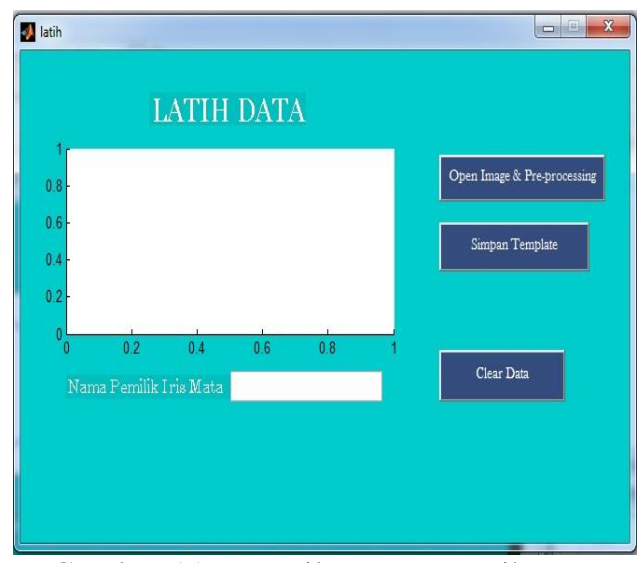

Gambar 11. Tampilan Menu Latih Data

Pada gambar 11 terdapat 3 tombol penting yaitu open image \& pre-processing, simpan template, dan clear data. Tombol open image \& pre-processing digunakan untuk mengambil citra yang akan dilatih kemudian citra diubah dari citra asli menjadi citra grayscale. Tombol simpan tempale digunakan untuk menyimpan nama pemilik iris mata dengan metode template matching yang hasilnya disimpan ke database sebagai data latih, dan tombol clear data untuk menghapus file-file yang didalam database. 


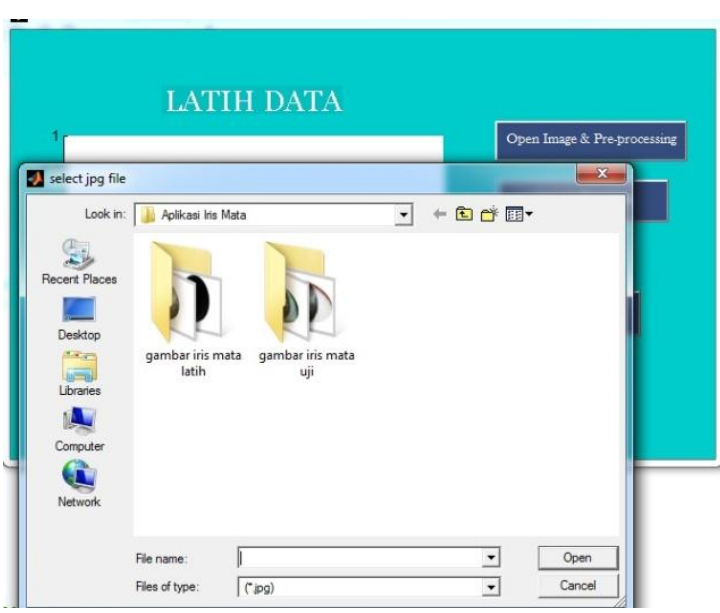

Gambar 12. Kotak Dialog Open Image

Pada gambar 12 terdapat kotak dialog yang merupakan pilihan untuk memilih gambar iris mata latih yang akan dijadikan untuk citra latih maupun gambar iris mata uji yang akan dijadikan citra uji. Kemudian selanjutnya tahap pre-processing.

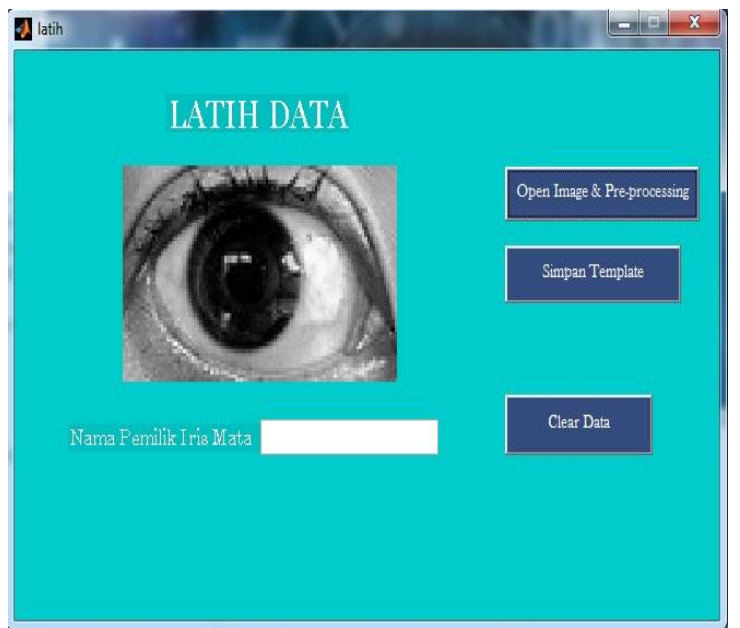

Gambar 13. Tampilan proses open image \& preprocessing

Pada gambar 13 merupakan tampilan memasukkan citra yang secara otomatis dari citra asli berubah menjadi citra grayscale sesuai dengan proses preprocessing. Setelah proses open image \& preprocessing maka proses selanjutnya adalah proses simpan template.

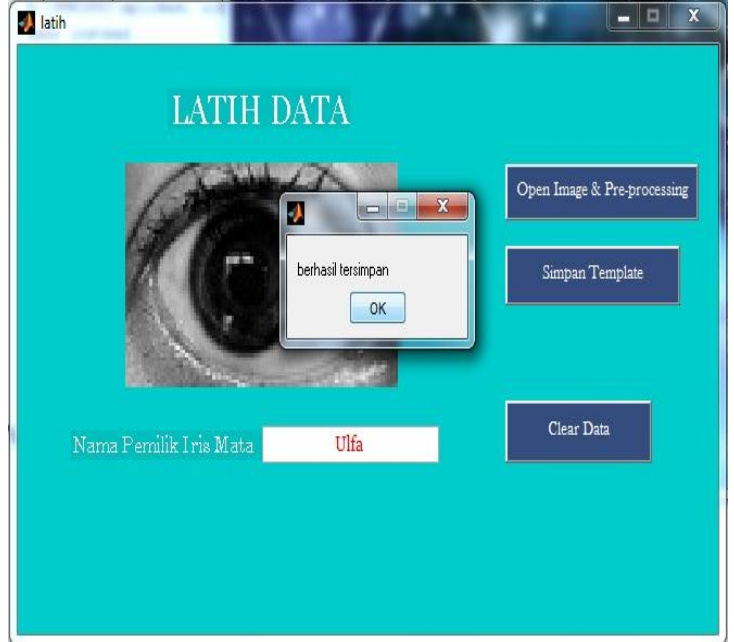

Gambar 14. Penyimpanan Template Kedalam Database

Pada gambar 14 dilakukan proses simpan template ke dalam database. Semua data latih akan diproses dalam pelatihan dan disimpan sebagai template. Apabila proses berhasil maka akan tampil sebuah message box berhasil disimpan. Kemudian selanjutnya adalah proses pengujian data.

\section{3) Tampilan Menu Uji Data}

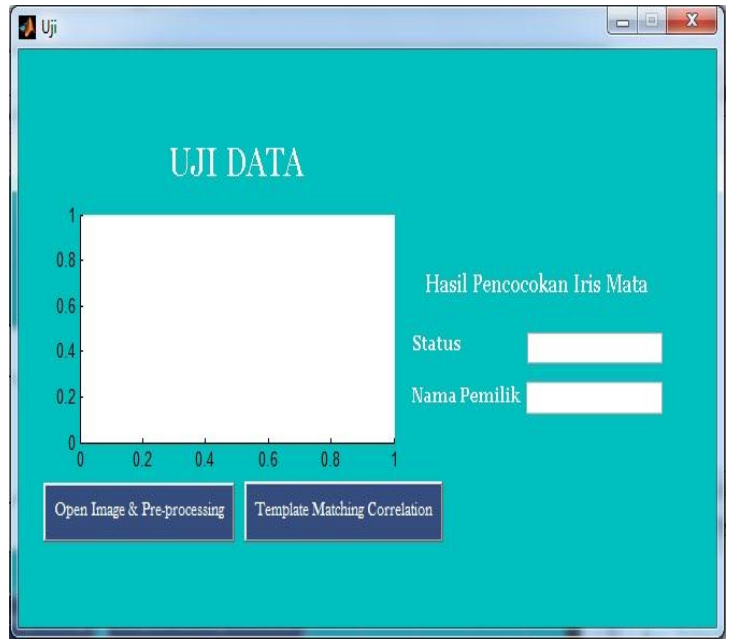

Gambar 15. Tampilan Menu Uji Data

Pada gambar 15 terdapat 2 tombol penting yaitu open image \& pre-processing dan template matching correlation. Tombol open image \& pre-processing digunakan untuk mengambil citra yang akan diuji kemudian citra diubah dari citra asli menjadi citra grayscale. Sedangkan tombol template matching correlation digunakan untuk mencocokan citra uji tersebut dengan mencari nilai terdekat dengan data latih yang dismpan dalam database dengan menggunakan correlation coefficient. 


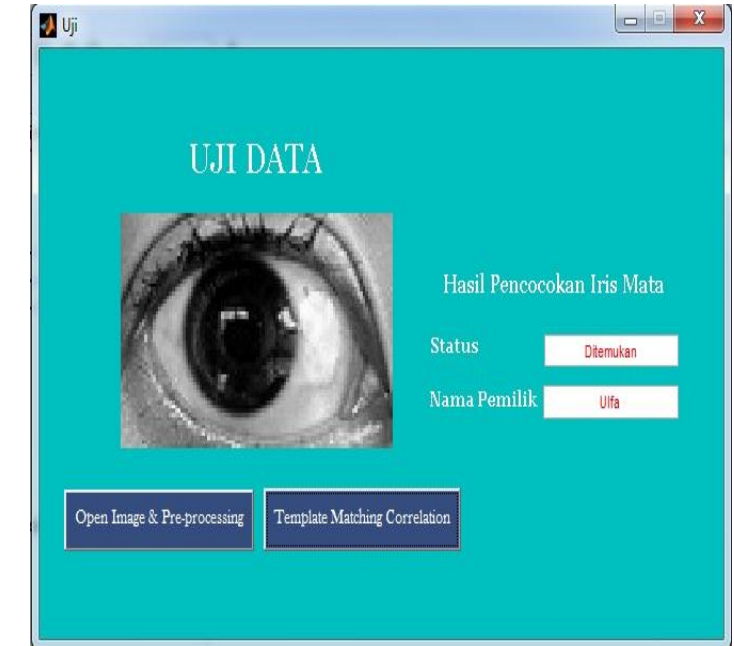

Gambar 16. Template Matching Correlation Berhasil

Pada gambar 16 memiliki langkah yang hampir sama dengan pelatihan data yaitu masukkan citra uji kedalam sistem pengenalan iris mata yaitu dengan masukkan data uji pada sistem dengan menekan tombol open image \& pre-processing kemudian citra yang dimasukkan akan otomatis berubah menjadi citra grayscale. Selanjutnya dilakukan proses pencocokan antara citra template dan citra uji menggunakan correlation coefficient. Apabila memiliki kecocokan dengan data latih akan muncul pada status ditemukan dan nama pemilik iris mata tersebut.

\section{E. Pembahasan}

Pada bagian ini dilakukan untuk mengetahui tingkat keberhasilan yang dilakukan dari aplikasi pengenalan iris mata menggunakan metode template matching correlation. Dalam menguji sistem diperlukan data latih dan data uji.

Berikut ini tabel citra latih dan table citra uji :

Tabel 1

\section{Citra Latih}

\begin{tabular}{|c|c|c|}
\hline No & Citra & Keterangan \\
\hline 1 & & Nama : Ulfa \\
\hline 2 & & Nama : Rima \\
\hline 3 & & Nama : Lina \\
\hline 4 & & Nama : Lela \\
\hline 5 & & \\
\hline
\end{tabular}

\begin{tabular}{|c|c|c|}
\hline No & Citra & Keterangan \\
\hline 6 & & Nama : Nadin \\
& & \\
\hline
\end{tabular}

Tabel 2

Citra Uji

\begin{tabular}{|c|c|c|c|}
\hline No & Citra & Nama & Keterangan \\
\hline 1 & & Ulfa.jpg & $\begin{array}{l}\text { Status } \quad \text { : Ditemukan } \\
\text { Nama Pemilik: Ulfa } \\
\text { Keterangan : Benar }\end{array}$ \\
\hline 2 & & Ulfa1.jpg & $\begin{array}{l}\text { Status } \quad \text { : Ditemukan } \\
\text { Nama Pemilik: Ulfa } \\
\text { Keterangan : Benar }\end{array}$ \\
\hline 3 & & Ulfa2.jpg & $\begin{array}{l}\text { Status } \quad \text { Ditemukan } \\
\text { Nama Pemilik: Ulfa } \\
\text { Keterangan : Benar }\end{array}$ \\
\hline 4 & & Ulfa3.jpg & $\begin{array}{l}\text { Status } \quad \text { : Ditemukan } \\
\text { Nama Pemilik: Ulfa } \\
\text { Keterangan : Benar }\end{array}$ \\
\hline 5 & & Ulfa4.jpg & $\begin{array}{l}\text { Status : Ditemukan } \\
\text { Nama Pemilik: Ulfa } \\
\text { Keterangan : Benar }\end{array}$ \\
\hline 6 & & $\begin{array}{c}\text { Ulfa } \\
\text { Kanan } \\
\text { Oppo.jpg }\end{array}$ & $\begin{array}{l}\text { Status } \quad \text { : Ditemukan } \\
\text { Nama Pemilik: Lina } \\
\text { Keterangan } \quad: \text { Salah }\end{array}$ \\
\hline 7 & & $\begin{array}{l}\text { Ulfa Kiri } \\
\text { Oppo.jpg }\end{array}$ & $\begin{array}{l}\text { Status : } \\
\text { Tidak ditemukan } \\
\text { Nama Pemilik: } \\
\text { Tidak ada nama } \\
\text { Keterangan : Salah }\end{array}$ \\
\hline 8 & & $\begin{array}{l}\text { Iris Kanan } \\
\text { Ulfa } \\
\text { Oppo.jpg }\end{array}$ & $\begin{array}{l}\text { Status : Ditemukan } \\
\text { Nama Pemilik: Ulfa } \\
\text { Keterangan : Benar }\end{array}$ \\
\hline 9 & & $\begin{array}{l}\text { Iris Kiri } \\
\text { Ulfa } \\
\text { Oppo.jpg }\end{array}$ & $\begin{array}{l}\text { Status : } \\
\text { Tidak ditemukan } \\
\text { Nama Pemilik: } \\
\text { Tidak ada nama } \\
\text { Keterangan : Salah }\end{array}$ \\
\hline 10 & & Rima.jpg & $\begin{array}{l}\text { Status } \quad \text { : Ditemukan } \\
\text { Nama Pemilik: Rima } \\
\text { Keterangan } \quad \text { : Benar }\end{array}$ \\
\hline 11 & & Rima1.jpg & $\begin{array}{l}\text { Status } \quad \text { Ditemukan } \\
\text { Nama Pemilik: Rima } \\
\text { Keterangan : Benar }\end{array}$ \\
\hline 12 & & Rima2.jpg & : Ditemukan \\
\hline
\end{tabular}




\begin{tabular}{|c|c|c|c|}
\hline No & Citra & Nama & Keterangan \\
\hline & & & $\begin{array}{l}\text { Nama Pemilik: Rima } \\
\text { Keterangan } \quad \text { : Benar }\end{array}$ \\
\hline 13 & & Rima3.jpg & $\begin{array}{l}\text { Status } \quad \text { : Ditemukan } \\
\text { Nama Pemilik: Rima } \\
\text { Keterangan } \quad \text { : Benar }\end{array}$ \\
\hline 14 & & Lina.jpg & $\begin{array}{l}\text { Status } \quad \text { : Ditemukan } \\
\text { Nama Pemilik: Lina } \\
\text { Keterangan } \quad \text { : Benar }\end{array}$ \\
\hline 15 & & Lela.jpg & $\begin{array}{l}\text { Status } \quad \text { : Ditemukan } \\
\text { Nama Pemilik: Lela } \\
\text { Keterangan } \quad \text { : Benar }\end{array}$ \\
\hline 16 & & Lela1.jpg & $\begin{array}{l}\text { Status } \quad \text { : Ditemukan } \\
\text { Nama Pemilik: Lela } \\
\text { Keterangan : Benar }\end{array}$ \\
\hline 17 & & Sita.jpg & $\begin{array}{l}\text { Status } \quad \text { : Ditemukan } \\
\text { Nama Pemilik: Sita } \\
\text { Keterangan } \quad: \text { Benar }\end{array}$ \\
\hline 18 & & Sita1.jpg & $\begin{array}{l}\text { Status : Ditemukan } \\
\text { Nama Pemilik: Sita } \\
\text { Keterangan : Benar }\end{array}$ \\
\hline 19 & & Sita2.jpg & $\begin{array}{l}\text { Status } \quad \text { : Ditemukan } \\
\text { Nama Pemilik: Sita } \\
\text { Keterangan }: \text { Benar }\end{array}$ \\
\hline 20 & & Nadin.jpg & $\begin{array}{l}\text { Status } \quad \text { : Ditemukan } \\
\text { Nama Pemilik: Nadin } \\
\text { Keterangan }: \text { Benar }\end{array}$ \\
\hline 21 & & $\begin{array}{l}\text { Nadin1.jp } \\
\mathrm{g}\end{array}$ & $\begin{array}{ll}\text { Status } & \text { : Ditemukan } \\
\text { Nama Pemilik: Nadin } \\
\text { Keterangan } \quad: \text { Benar }\end{array}$ \\
\hline 22 & & Citra.jpg & $\begin{array}{l}\text { Status : } \\
\text { Tidak ditemukan } \\
\text { Nama Pemilik : } \\
\text { Tidak ada nama } \\
\text { Keterangan } \quad: \text { Benar }\end{array}$ \\
\hline
\end{tabular}

Berdasarkan pengujian dengan 22 data uji maka diperoleh kesimpulan sebagai berikut :

1. Pemilihan citra latih yang akan dijadikan template dan citra uji sangat mempengaruhi hasil pencocokan, karena perbedaan pengambilan citra dan kualitas citra sangat mempengaruhi hasil.

2. Pengujian yang dilakukan dengan menggunakan 6 citra latih dan 22 citra uji.

3. Dari 22 citra uji 19 citra uji berhasil dikenali dengan status dan nama yang benar, 3 citra uji tidak berhasil dikenali.
4. Hasil pengujian dari 22 citra didapatkan persentasi keberhasilan sistem adalah $86,36 \%$.

\section{PENUTUP}

Pada bagian ini diuraikan kesimpulan dan saran dari perancangan sistem pengenalan iris mata menggunakan metode Template matching correlation.

\section{A. Kesimpulan}

Berdasarkan hasil dari studi literatur, analisis, perancangan dan pengujian yang telah dilakukan, maka dapat disimpulkan sebagai berikut :

1. Pengujian yang dilakukan pada sistem pengenalan iris mata pengambilan citra dan kualitas citra sangat mempengaruhi hasil pengujian.

2. Dari hasil pengujian dapat diketahui bahwa metode template matching correlation tepat untuk pengenalan iris mata karena memiliki hasil pengujian yang pasti.

3. Hasil pengenalan iris mata pada proses pengujian yang dilakukan mencapai $86,36 \%$ dapat dikatakan cukup akurat untuk sistem pengenalan iris mata.

B. Saran

Adapun saran yang dapat digunakan untuk perkembangan penelitian selanjutnya yaitu sebagai berikut :

1. Agar mendapatkan keakuratan yang lebih tinggi dibutuhkan template yang cukup banyak untuk menjadi pembanding dengan citra yang lain.

2. Pada penelitian selanjutnya diharapkan melakukan sistem pengenalan iris mata yang dapat menerima citra masukan dari berbagai jenis file citra.

\section{REFERENSI}

[1] S. Rahman and M. Ulfayani.T, "Perancangan Aplikasi Identifikasi Biometrika Telapak Tangan Menggunakan Metode Freeman Chain Code," CESS (Journal Comput. Eng. Syst. Sci., vol. 2, no. 2, pp. 64-73, 2017.

[2] I. Hermawan, "Rancang Bangun Sistem Pendeteksi dan Pengenalan Angka Pada Meteran Air PDAM Menggunakan Metode Template Matching Correlation," J. Teknol. Terpadu, vol. 1, no. 2, pp. 55-61, 2015.

[3] E. Yuliansyah, R. Magdalena.M.T, and Estananto, "Sistem Identifikasi Iris Mata Dengan Indefendent Component Analysis Dan Klasifikasi K-Nearest Neighbor," e-Proceeding Eng., vol. 4, no. 2, pp. 1810-1815, 2017.

[4] RumahBelajar, "Digital Image Sensor," 2013. [Online]. Available: http://www.rumahbelajar.org.

[5] J. Laseduw, "Pencegah Penyakit Katarak," 2013. [Online]. Available: $111 \mathrm{http}: / /$ necturajuice.com.

[6] P. Hidayatullah, Pengolahan Citra Digital Teori Dan Aplikasi Nyata. Bandung: Informatika, 2017.

[7] F. Mahardika, K. Agus.Purwanto, and D. Intan.Surya.Saputra, "Implementasi Metode Waterfall Pada Proses Digitalisasi Citra Analog," J. Ilm. Pendidik. Tek. Elektro, vol. 2, no. 1, pp. 
63-72, 2016.

[8] Dhanarful, "Pengenalan Pola," 2015. [Online]. Available: http://slideshare.net/education/dhanarful/pengenal an pola-part-2.

[9] D. Putra, Pengolahan Citra Digital. Yogyakarta: ANDI, 2010.

[10] Pelajarindo, "Simbol Flowchart," 2017. [Online]. Available: http://pelajarindo.com.

[11]E. Amri.jaya, "Perancangan Sistem Informasi Persediaan Stock Farfum Dengan Menggunakan Bahasa Pemrograman Visual Basic.net Dan Database Access Pada Toko Gofha Perfume," J. Sains dan Teknol., vol. 16, no. 1, pp. 114-186, 2016.

[12] L. Hakim, M. Imron.Rosadi, and R. Hadi.Prayoga, "Deteksi Lokasi Citra Iris Menggunakan Threshold Linear Dan Garis Horisontal Imajiner," Semin. Nas. Teknol. Informasi, Komun. dan Apl., vol. 4, 2017.

[13] Andriana and Zulkarnain, "Aplikasi Biometrik untuk Identifikasi Iris Menggunakan Glcm (Gray Level Co Matrix) dan Hough Transform," J. Ilmuilmu Sos. Hum. Univ. Langlangbuana, vol. XVI, 2014.

[14]T. Tri.Pamungkas, R. Rizal.Isnanto, and A. Ajulian.Zahra, "Pengenalan Plat Nomor Kendaraan Menggunakan Metode Template Matching Dan Jarak Canberra," TRANSIENT, vol. 3, no. 2, pp. 166-173, 2014. 